\title{
AN APPROACH FOR THE MULTI-CRITERIA DERIVATION OF LIGHTWEIGHT POTENTIAL
}

\author{
F. Laufer ${ }^{凶}$, D. Roth and H. Binz \\ University of Stuttgart, Germany \\ $\square$ felix.laufer@iktd.uni-stuttgart.de
}

\begin{abstract}
Lightweight potential is a powerful indicator - but not as powerful as it could be. Current methods for analyzing a product's potential to be reduced in mass only deal with a few of the most important criteria for lightweight design. This paper presents an approach transferring cost-benefit analysis to the holistic derivation of lightweight potential. The approach is able to deal with different types of criteria supporting the designer in indentifying the most promising components for mass reduction. An evaluation example is given showcasing a tooling machine.
\end{abstract}

Keywords: lightweight design, early design phase, cost-benefit analysis, case study

\section{Introduction}

Available technologies for conducting lightweight design are numerous. The range of high-strength, light materials has grown, the calculation of lightweight structures has increased in efficiency, and the effectiveness of lightweight-manufacturing techniques has improved. Confronted with these options, lightweight designers must choose which technologies or combination thereof best suit their needs. This decision is part of the conceptual-design phase (Klein, 2013), where the designer aims to match an appropriate technology to a certain product part to be reduced in mass. The question asked at this point is often as follows: Where can lightweight design be applied? Nonetheless, to steer lightweight effort in the most effective direction, the designer should first assess the potential of different product parts. A holistic lightweight-design-potential assessment of the entire product enables resources regarding mass reduction to be distributed based on several boundary conditions (Posner et al., 2014). The result of this assessment is an identification of components or assemblies for which the most promising mass reductions can be achieved, which aims to answer the question: Where should lightweight design be applied? The phrasing "where should" refers to the motivation for applying lightweight design as an optimization technique in the first place. When optimizing a tooling machine with regard to lightweight design, for instance, the motivation of improving working performance might lead to a mass reduction in dynamic components like the machine spindle. If, however, the motivation is to reduce manufacturing costs for the same machine, static components like the casing might become the focus of lightweight design. In order to derive reliable lightweight potential with respect to a specific product and design case, all relevant motivations or derived criteria for this particular lightweight scenario have to be taken into account (Laufer et al., 2019). One measurable criterion for the motivation of improving working performance, for instance, might be the cycle time in the case of a tooling machine. 


\section{Problem statement and goal}

The application fields of methods for deriving lightweight potential are wide-ranging and spread over several industries. However, the different methods often only cover a small selection of the lightweight criteria most relevant for the particular industry (Laufer et al., 2019). The flexibility of these methods to be applied to other lightweight design scenarios is often limited because the adaptability to versatile criteria sets is not given (see inter alia Alonso et al., 2012; Lewis et al., 2014; Albers et al., 2018). On the one hand, when deriving lightweight potential, this reduces the general applicability of these methods to different lightweight contexts. On the other hand, a particular set of criteria relevant for a certain lightweight-design scenario might not be representable with one of the existing methods, or even a combination thereof. One frequently occurring problem is that the methods do not have an abstraction level that allows criteria to be balanced with different units. However, assessment methods are nothing novel for engineering problems. Cost-benefit and cost-effectiveness analyses, for instance, are commonly used in engineering contexts in general (inter alia Markel and Simpson, 2007) and in lightweight design contexts in particular (inter alia Hao et al., 2016), and their inherent logic facilitates a differentiated comparison and assessment of various criteria with various units. Moreover, while studying the literature on that topic (see Section 4 and 5), as well as working on lightweight-optimization projects with several industrial partners, the authors determined the general applicability of these methods to various assessment problems.

The goal of this paper is thus twofold: firstly, to examine existing methods for deriving lightweight potential in terms of their deficits in handling different criteria and, secondly, to illustrate that lightweight potential can be derived in a holistic manner by implementing the cost-benefit analysis in lightweight design regardless of the lightweight criteria at hand. Finally, the usefulness of the approach will be illustrated in a case study concerning a processing machine.

\section{Methodology}

The Design Research Methodology (DRM) set out by Blessing and Chakrabarti (2009) provides the methodological framework for research in this paper. The clarification of the research forms part of Sections 1 to 3 (first step of the DRM). Descriptive Study I is based on the authors' previous work published at ICED19 (Laufer et al., 2019) and will examine identified methods for deriving lightweight potential (the second step of the DRM). This section addresses the first research question (RQ):

- What are the deficits of existing methods for deriving lightweight potential with respect to the inclusion of relevant criteria in lightweight design? (Section 4)

In the third step of the DRM, the Prescriptive Study, the implementation and operationalization of the cost-benefit analysis for lightweight design will be carried out to answer the second RQ:

- Which adjustments have to be made to apply cost-benefit analyses to the derivation of lightweight potential? (Section 5)

In Descriptive Study II (last step of the DRM), the implemented approach will be evaluated through a case study of a processing machine. This application example is used to answer the third RQ:

- Is the cost-benefit analysis flexible and useful for analyzing lightweight potential? (Sections 6 and 7)

Subsequently, the paper is critically discussed, the results of the implemented approach are reviewed, and an outlook of future work is given (Section 7).

\section{Methods for deriving lightweight potential: A literature perspective}

Since lightweight potential is a powerful indicator in many industries, the subject has been the focus of methodological research over the past years. The automotive sector and the machine-tool industry are the two leading industries for the development of lightweight-design solutions in general and methodological support for deriving lightweight potential in particular (Laufer et al., 2019). The reason for the continuous development of methods in these two fields is the narrow band in which the application of lightweight- 
design solutions falls. Here, "narrow band" describes the ratio between the costs invested and the mass reduced. While sectors like aviation and aerospace - in which lightweight design has exceptionally high relevance - are able to spend approximately $€ 500$ to $€ 3000$ per saved kilogram, respectively, the sum in the automotive industry ranges between $€ 7$ and $€ 18$ per kilogram, for instance (Klein, 2013). The consideration of where to apply lightweight design is therefore much more challenging from a cost perspective, which promotes the development of supporting assessment methods. However, as stated in Section 2, one main shortcoming of these methods is the lack of options for dealing with diverse criteria in lightweight design (for all relevant criteria, see Laufer et al. (2019)). This section should therefore answer the first research question: What are the deficits of existing methods for deriving lightweight potential with respect to the inclusion of relevant criteria in lightweight design?

Table 1 provides an overview of the methods investigated. The focus of this tabular summary is on the identified main deficits (see last column of Table 1). Moreover, it provides systematic access to recently published methods with their different abstraction levels and the way in which lightweight potential is derived.

Table 1. Methods for deriving lightweight potential and their deficits

\begin{tabular}{|c|c|c|c|}
\hline Reference & $\begin{array}{c}\text { Abstraction } \\
\text { level [unit] }\end{array}$ & Derivation of lightweight potential & Main deficit \\
\hline $\begin{array}{l}\text { Albers et al., } \\
2018\end{array}$ & $\begin{array}{l}\text { Functional } \\
\text { level }[-]\end{array}$ & $\begin{array}{l}\text { Linear regression over functional } \\
\text { importance }\end{array}$ & $\begin{array}{l}\text { Exclusion of the reciprocal } \\
\text { influence of included criteria }\end{array}$ \\
\hline $\begin{array}{l}\text { Alonso et al., } \\
2012\end{array}$ & $\begin{array}{l}\text { Mass decom- } \\
\text { pounding co- } \\
\text { efficient }[-]\end{array}$ & $\begin{array}{l}\text { Components with highest secondary } \\
\text { mass-reduction effect }\end{array}$ & $\begin{array}{l}\text { Abstraction level limits the } \\
\text { inclusion of different criteria }\end{array}$ \\
\hline $\begin{array}{l}\text { Caldwell et al., } \\
2013\end{array}$ & $\begin{array}{l}\text { Functional } \\
\text { indicator }[-]\end{array}$ & $\begin{array}{l}\text { Ranking of parts using estimated } \\
\text { mass reduction potential }\end{array}$ & $\begin{array}{l}\text { Limited to consideration of } \\
\text { assembly indicators }\end{array}$ \\
\hline $\begin{array}{l}\text { Cheah and } \\
\text { Heywood, } 2011\end{array}$ & $\begin{array}{l}\text { Normalized } \\
\text { measure [\%] }\end{array}$ & $\begin{array}{l}\text { Metric: emphasis on reducing fuel } \\
\text { consumption }\end{array}$ & $\begin{array}{l}\text { Limited to consideration of } \\
\text { fuel-consumption rate }\end{array}$ \\
\hline Hao et al., 2016 & $\begin{array}{l}\text { Effectiveness } \\
\text { level } \\
{[¥ /(\mathrm{L} / \mathrm{km})]}\end{array}$ & $\begin{array}{l}\text { Minimal cost for local maximum in } \\
\text { saved mass through lightweight } \\
\text { technology }\end{array}$ & $\begin{array}{l}\text { Abstraction level limits the } \\
\text { inclusion of different criteria }\end{array}$ \\
\hline $\begin{array}{l}\text { Kroll et al., } \\
2011\end{array}$ & None $[-]$ & $\begin{array}{l}\text { Based on individual process } \\
\text { characteristics of different tooling } \\
\text { machines }\end{array}$ & $\begin{array}{l}\text { Lack of abstraction level does } \\
\text { not allow implementation }\end{array}$ \\
\hline $\begin{array}{l}\text { Laufer et al., } \\
2018\end{array}$ & $\begin{array}{l}\text { Kinetic and } \\
\text { potential } \\
\text { energy }[\mathrm{J}]\end{array}$ & $\begin{array}{l}\text { Comparison of the different energy } \\
\text { levels }\end{array}$ & $\begin{array}{l}\text { Limited to consideration of } \\
\text { different energies }\end{array}$ \\
\hline $\begin{array}{l}\text { Lewis et al., } \\
2014\end{array}$ & None $[-]$ & $\begin{array}{l}\text { Comparison of the reduction of fuel } \\
\text { consumption and GHG emissions }\end{array}$ & $\begin{array}{l}\text { Lack of abstraction level does } \\
\text { not allow implementation }\end{array}$ \\
\hline $\begin{array}{l}\text { Luedeke and } \\
\text { Vielhaber, } 2014\end{array}$ & $\begin{array}{l}\text { Weight-impact } \\
\text { factors }[-]\end{array}$ & $\begin{array}{l}\text { Components with highest secondary } \\
\text { mass-reduction effect }\end{array}$ & $\begin{array}{l}\text { Abstraction level limits the } \\
\text { inclusion of different criteria }\end{array}$ \\
\hline $\begin{array}{l}\text { O'Reilly et al., } \\
2016\end{array}$ & $\begin{array}{l}\text { Energy over } \\
\text { lifecycle }[\mathrm{J}]\end{array}$ & $\begin{array}{l}\text { Convergence criteria for minimum } \\
\text { lifecycle energy }\end{array}$ & $\begin{array}{l}\text { Limited to consideration of } \\
\text { different energies }\end{array}$ \\
\hline $\begin{array}{l}\text { Posner et al., } \\
2014\end{array}$ & $\begin{array}{l}\text { Functional } \\
\text { level }[-]\end{array}$ & $\begin{array}{l}\text { Comparison of the current and desired } \\
\text { mass }\end{array}$ & $\begin{array}{l}\text { Limited to consideration of } \\
\text { customer requirements }\end{array}$ \\
\hline
\end{tabular}

This analysis shows that every method investigated has deficits regarding the holistic implementation of different criteria relevant to lightweight design. As pointed out in Section 2, the authors identified potential for applying the cost-benefit analysis (CBA) to the assessment of versatile criteria. The basic procedure of the CBA is thus adapted to the derivation of lightweight potential. The following section will introduce a new approach that incorporates a CBA into a lightweight-design framework for the multi-criteria derivation of lightweight potential. This approach should support the designer in systematically assessing optimal product components for mass reduction. 


\section{Approach for multi-criteria derivation of lightweight potential}

The analysis of cost and benefit is well established in various fields for assessment problems (Mishan, 1972). In engineering design, for instance, the method is used to assess innovations such as plug-in hybrid technology for electric vehicles (Markel and Simpson, 2007). Regarding compact, lightweight automobiles incorporating aluminum and high-strength steel, Kim et al. (2008) similarly investigate the cost and benefit for manufacturers and consumers. Farooq et al. (2018) employ a CBA to innovative manufacturing processes to evaluate the application of super-vacuum die-casting for aluminum alloys, yet the use of a CBA to derive lightweight potential is not represented in literature. For this reason, this section firstly deals with the basics of the CBA and, secondly, aims to anchor it methodologically in the derivation of lightweight potential. The corresponding question to answer is as follows: Which adjustments have to be made to apply cost-benefit analyses to the derivation of lightweight potential?

\subsection{Cost-benefit analysis}

A cost-benefit analysis is a systematic approach for estimating the strengths and weaknesses of alternatives, supporting designers in identifying the greatest benefit against the invested costs. Benefits are non-monetary factors that are ultimately compared against costs. On the one hand, all the aspects beneficial to the project are balanced on a dimensionless abstraction level to form the total benefit. Conversely, the costs comprise the investment accumulated in the project (e.g., manufacturing costs and labor costs). The concept and basic procedure of this analysis are straightforward, yet obtaining accurate estimates of costs and benefits can be challenging depending on the data available, the time for accurate calculation, and the progress of the project. To gather all information needed, some assumptions have to be made that are checked for robustness later on (Cellini and Kee, 2015). Moreover, CBAs are not confined to appraising complete investment projects, but are also employed to determine whether the capacity of existing projects should be extended (Mishan, 1972). Within this paper, the "project" constitutes the lightweight optimization of a product.

The procedure is clustered into several steps, starting with setting the framework for the analysis as well as the target system, including all stakeholders and boundary conditions. After that, all relevant costs and benefits for the product are collected and categorized. In terms of benefits, the next step is weighting the individual benefits - represented by measurable criteria - to clarify preferences among the stakeholders. Thereafter, the weighted benefit criteria and the costs are quantified. The quantification then allows dimensionless numbers to be assigned to various product components depending on their performance for the individual criteria (i.e., degree of fulfilment). In the paper's lightweight context, this might mean how much value is gained by reducing the components' mass by one kilogram on the one hand (net benefit), and how much it costs to reduce one kilogram on the other (net cost). Comparing benefits against costs for the individual parts then yields the cost-benefit ratio. Finally, a sensitivity analysis is performed to assess the influence of the most relevant assumption made earlier in the analysis. With these results, a recommendation can be made where appropriate (Cellini and Kee, 2015; Rinza and Schmitz, 1992).

\subsection{Application of a CBA to the derivation of lightweight potential}

The straightforward procedure of a CBA as described above enables benefit and cost to be considered separately. As described in Section 4, the main deficit of existing methods lies in the lack of an abstraction level capable of combining criteria with different units. The calculation of the net benefit in a CBA is one way of addressing this problem (Rinza and Schmitz, 1992). As will be shown in the case study in Section 6, the net benefit will serve as an indicator for a component's lightweight potential. As lightweight-design projects are often judged on the financial resources consumed (Klein, 2013), the implementation of the cost perspective in relation to the net benefit is the consequential step often demanded in lightweight literature (see inter alia Albers et al., 2018).

Figure 1 shows the approach of using a CBA developed to assess the various lightweight potentials of a product with regard to different components. This framework follows the classical CBA except for one adjustment concerning the correlation between the various product components and benefit criteria. While 
every alternative has a certain value regarding a certain benefit criterion in a classical CBA, a CBA for lightweight potential must consider one intermediate step. The necessity of this step is explained using the example of a tooling machine. If, for instance, the operational energy of a tooling machine constitutes one benefit criterion for an assessment task, the machine components actually consuming the energy can be compared to each other. Here, a classical CBA gathers the energy-consumption figures and assigns them to the machine parts directly involved in the component-criteria correlation. If, however, the benefit criterion is a reduction in operational energy (through mass reduction), an intermediate step must first determine how much operational energy is actually saved by reducing the mass (in this case mass subject to motion). After that, the components subject to motion can be assigned to the reduction of operational energy, depending on how much mass they have and how energy-intensive their motions are. Subsequently, this extra step firstly correlates benefit criteria to reduced mass (Figure 1, blue-framed boxes) before it is possible to assign the components to the reduced mass, thereby determining the targeted, actual component-criteria correlation.

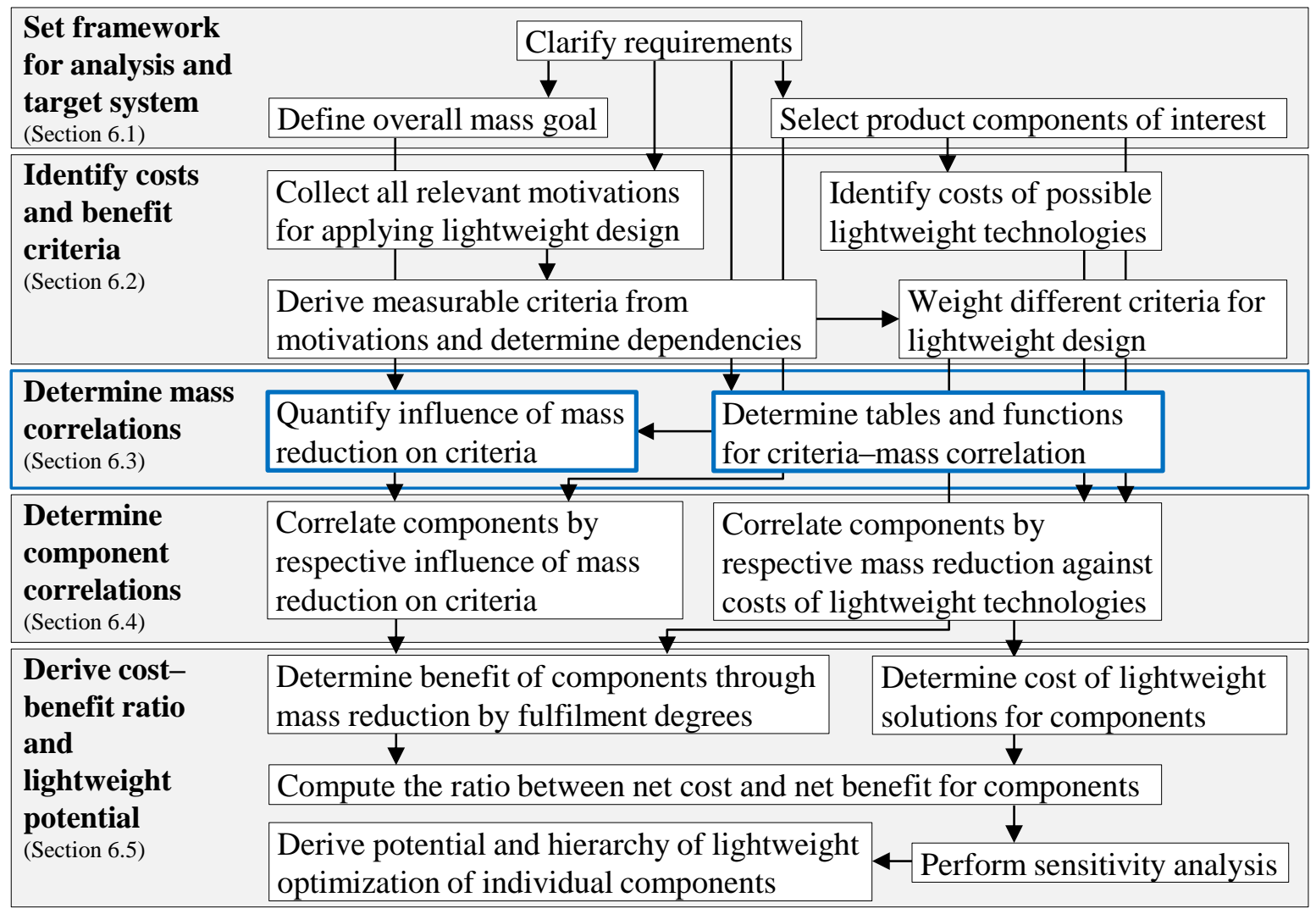

Figure 1. Approach for using a cost-benefit analysis to derive lightweight potential

Implementing this adjustment within the classical CBA procedure (Cellini and Kee, 2015; Rinza and Schmitz, 1992), Figure 1 depicts the framework developed for deriving lightweight potential. The process passes through the five methodological clusters (grey boxes) consecutively from top to bottom.

\section{Evaluation of the approach: Case study of a processing machine}

This section addresses the application and evaluation of the framework derived above. A processing machine is therefore investigated with regard to deriving lightweight potential. The research question central to Sections 6 and 7 is as follows: Is the cost-benefit analysis flexible and useful for analyzing lightweight potential?

The processing machine illustrated in Figure 2 is an application example from one of the authors' industrial cooperation partners and will serve as an evaluation example. The machine comprises a static frame and a motion unit split into three assemblies (horizontal cart, vertical cart, and operating fork) and performs a 2axis cyclical motion. Both axes are driven by an identical gear motor in combination with a belt. The machine operates within the frame and transports stacks of cardboard boxes from the left to the right. 


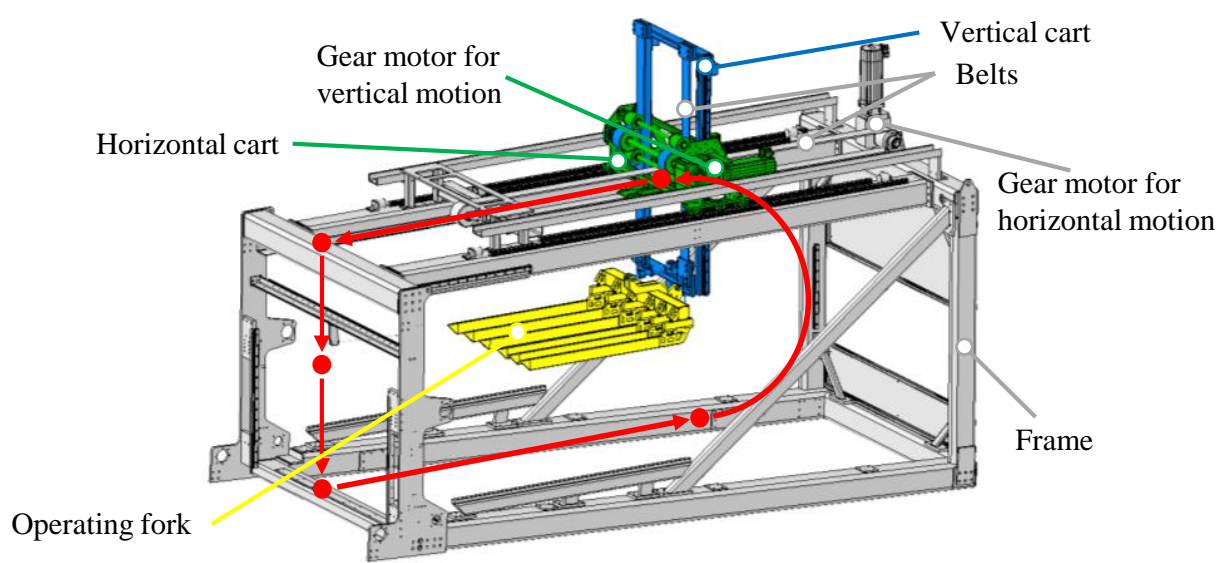

Figure 2. Isometric view of the 2-axis processing machine with motion profile (red path)

\subsection{Framework for the analysis and target system}

As the processing machine is a higher-end product than its competitors, a fast cycle time is one main requirement. To perform on a high-quality process level, the machine must be designed stiff so that the large forces introduced by the motion unit do not cause the frame to oscillate. The lightweightdesign project therefore focusses on three assemblies of the motion unit (horizontal cart, vertical cart, and operating fork) and targets a $30 \%$ mass reduction. The frame will be investigated separately in another project with the focus of reinforcing the structure while maintaining the mass.

\subsection{Identification of costs and benefits}

Four main motivations (benefit criteria) for performing lightweight design on the processing machine are isolated and weighted against each other by comparing them in pairs. The first motivation is to reduce the oscillations of the machine. Because the influence of mass on the oscillations of a system is difficult to predict, the benefit criterion applied is lowering of the total center of gravity (17\% weighting) of the entire machine. Lowering the center of gravity (c.g.) will shorten the lever arm from the entire machine to the ground, thus reducing oscillation amplitudes. Secondly, the effective power required (17\% weighting) to operate the parts subject to motion should be reduced as an outcome of lightweight design. The power can be measured directly in watts. The third driver for reducing the machine's mass is to increase the performance (33\% weighting), whereby the benefit criterion to be quantified here is the feasible acceleration (currently $9 \mathrm{~m} / \mathrm{s}^{2}$ ). Lastly, the manufacturing costs should be reduced, which might conflict with the other benefit criteria. Therefore, because use of lighter material and topology-optimized structures are one possible scenario in the lightweight project (often resulting in higher costs), the benefit criterion for reducing production costs relates to the secondary mass savings (33\% weighting) with regard to the motion unit's two gear motors alone. Reducing the mass of moving assemblies could lead to a smaller gear motor with consequently reduced costs. At this early stage of the project, the possible costs for lightweight design are difficult to estimate. The project partners agreed to derive the benefits (i.e., lightweight potential) first to obtain a direction and preference for the lightweight optimization. Based on that, lightweight designs will be conceptualized to yield a more precise cost estimation for deriving individual cost-benefit ratios for the assemblies at a later stage.

\subsection{Determination of the correlations of mass and benefit criteria}

Determining the correlation between the first benefit criterion - lowering the c.g. - is straightforward. The shift of the c.g. for the entire machine is proportionately influenced by the mass reduced. The direction of the shift (upward or downward along the gravitational axis) depends on the location of the assembly to be reduced. The calculation follows Formula (1):

$$
z_{\text {total }}=\frac{\sum z_{i} \cdot m_{i}}{\sum m_{i}}
$$


Here, $z_{\text {total }}$ is the location of the entire machine's c.g. (total) and of the assemblies' c.g. (i), respectively, while $\mathrm{m}_{\mathrm{i}}$ represents the assemblies' mass. The physical description of effective power - which is work $(W)$ over time - enables the mass to be correlated to the second benefit criterion, yielding Formula (2):

$$
P_{e f f}=\frac{W}{t}=\frac{m \cdot s \cdot a}{t}
$$

Here, $P_{\text {eff }}$ is the effective power, $m$ the assembly's mass, $s$ the distance travelled within the motion profile (see Figure 2), $a$ the acceleration, and $t$ the time needed.

The third benefit criterion is the performance increase. Here, several factors complicate correlation. While mass and acceleration remain proportionate to force, acceleration appears to improve with mass reduction progressively. This relation is derived from four data points given (see Figure 3). There are two reasons for this: Firstly, by reducing the mass, oscillations also reduce (as intended, see the first benefit criterion), making an increase in maximum acceleration feasible. Secondly, by applying lightweight design, the gearmotor combination can be modified (i.e., lighter motor), thereby further increasing achievable performance. This factor is a secondary effect and overlaps with the benefit criterion secondary mass savings. In the CBA, these relationships between criteria appear critical due to their subsequent over- or undervaluation. This might distort the analysis and must be treated carefully (Rinza and Schmitz, 1992). However, secondary mass savings are measured in euros as an individual criterion within this analysis, hence the overlap is assessed as marginal, although it will be checked again after an initial lightweight concept is developed.

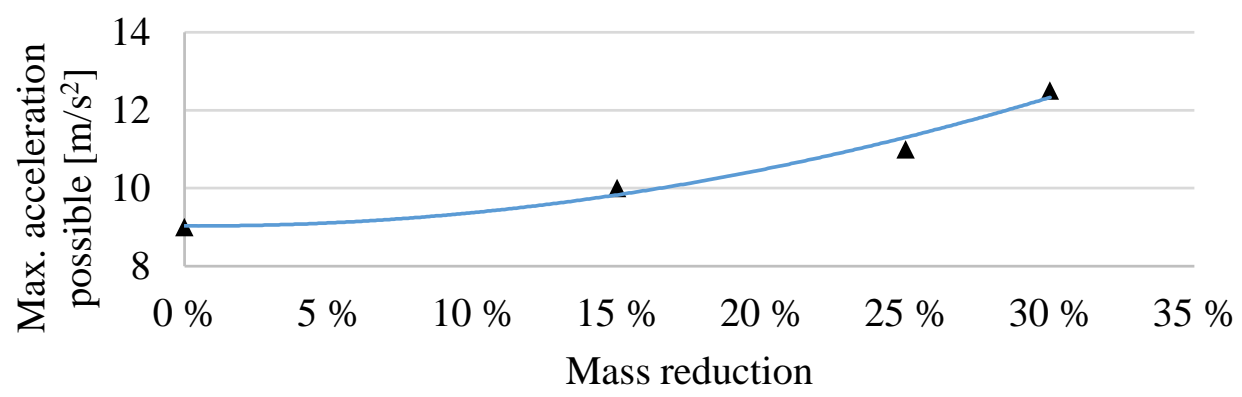

Figure 3. Acceleration curve against varying degrees of mass reduction

The correlation between mass and the last criterion secondary mass savings is an incremental correlation due to the available gear-motor combinations that can be downsized if the moving assemblies lose mass. For reasons of confidentiality, the authors are not permitted to publish any concrete costs for these actuators. However, the relative cost savings are shown in Table 2.

Table 2. Secondary mass savings for gear-motor unit through mass reduction

\begin{tabular}{|l|l|l|l|l|l|}
\hline Reduction in mass [\%] & $\mathbf{0}$ & $\mathbf{1 5}$ & $\mathbf{2 5}$ & $\mathbf{3 0}$ & $\mathbf{5 5}$ \\
\hline Relative cost savings [\%] & 0 & 14 & 11 & 11 & 43 \\
\hline
\end{tabular}

The relatively high costs savings of $14 \%$ with a mass reduction of $15 \%$ (third column in Table 2) can be explained by a special gear-motor combination provided by the cooperation partner's supplier. This fact is unique to this lightweight-design project, yet the implications of this singularly reciprocal cost structure must be considered when assessing lightweight potential. Furthermore, the granularity of the steps chosen is a result of both intense screening of the product's inherent dynamics and the expertise of the cooperation partner in designing processing machines.

\subsection{Determining assembly correlations}

After determining the correlation of the benefit criteria to mass, the latter facilitates correlation to the assemblies. An unweighted reduction in mass of $30 \%$ for every component yields improvements with regard to each of the benefit criteria shown in Table 3. Due to the different possible positions of the motion unit during motion, the shift of the c.g. is calculated at the most disadvantageous position for oscillations, which is the top horizontal path (see Figure 2). 
Table 3. Criteria-based improvements of the product assemblies before/after mass reduction

\begin{tabular}{|l|l|c|c|c|c|c|c|c|}
\hline & & \multicolumn{3}{|c|}{ Horizontal cart } & \multicolumn{2}{c|}{ Vertical cart } & \multicolumn{2}{c|}{ Operating fork } \\
\hline Mass & Unit & Before & After & Before & After & Before & After \\
\hline Shift of c.g. & {$[\mathrm{kg}]$} & 229 & 160 & 145 & 102 & 30 & 21 \\
\hline Effective power & {$[\mathrm{m}]$} & 0 & 0.025 & 0 & 0.022 & 0 & 0.001 \\
\hline Performance & {$[\mathrm{kW}]$} & 5.77 & 4.04 & 8.70 & 6.09 & 1.80 & 1.26 \\
\hline Secondary mass savings & {$\left[\mathrm{m} / \mathrm{s}^{2}\right]$} & 9 & 12.5 & 9 & 12.5 & 9 & 12.5 \\
\hline & {$[\%]$} & 0 & 11 & 0 & 11 & 0 & 11 \\
\hline
\end{tabular}

These figures form the basis for deriving the degree of fulfilment. This correlation to a dimensionless abstraction level enables all benefit criteria to be balanced against one figure for each individual assembly, which then constitutes the assembly's net benefit (i.e., lightweight potential).

\subsection{Derivation of cost-benefit ratio and lightweight potential}

The final step of the CBA for deriving lightweight potential starts with the determination of the fulfilment degrees. These degrees range from 0 to 6 and can be correlated to the figures of the benefit criteria in different functional relations (Rinza and Schmitz, 1992). Regarding the processing machine, the relations were set linearly for every criterion after weighting the different options with the cooperation partner (calculable by rule of three). The maximum number of points (i.e., 6) was given for a $0.2 \mathrm{~m}$ shift of the total c.g. for a reduction of the effective power of $10 \mathrm{~kW}$, for a performance increase up to $12.5 \mathrm{~m} / \mathrm{s}^{2}$, and for a secondary saving of $43 \%$ in gear-motor costs for each individual assembly, respectively. With respect to the performance, it must be mentioned that the horizontal cart is involved in only $44 \%$ of the motion cycle, which reduces this assembly's influence on the performance increase. For the cost savings through secondary mass it is also relevant that only one of the gear motors are involved horizontal cart's motion (i.e., $50 \%$ of gear motors used), whereas both gear motors are involved in the motion of the vertical cart and the operating fork (i.e., $100 \%$ of gear motors used). With regard to both criteria, the mass of each assembly relative to the entire motion unit's mass also factors in the calculation of these two fulfilment degrees. Finally, the net benefit $(B)$ can be calculated using Formula (3), where $w_{\mathrm{i}}$ is the criterion's weighting and $f_{\mathrm{i}}$ is the degree of fulfilment for each assembly $(i)$ :

$$
B_{n e t}=\sum_{i} w_{i} \cdot f_{i}
$$

Table 4 lists the various assemblies against the benefit criteria and their respective degrees of fulfilment. Consequently, the net benefit can be balanced against the weightings of the criteria.

Table 4. Net benefits of the various assemblies based on the benefit criteria

\begin{tabular}{|c|c|c|c|c|}
\hline & & Horizontal cart & Vertical cart & Operating fork \\
\hline & Weight & \multicolumn{3}{|c|}{ Degree of fulfilment (dimensionless; 0 to 6 ) } \\
\hline Shift of c.g. & 0.17 & 0.75 & 0.66 & 0.04 \\
\hline Effective power & 0.17 & 1.04 & 1.57 & 0.32 \\
\hline Performance & 0.33 & 1.49 & 2.15 & 0.45 \\
\hline Secondary mass savings & 0.33 & 0.44 & 0.56 & 0.12 \\
\hline Net benefit $\left(B_{\text {net }}\right)$ & & 0.94 & 1.28 & 0.25 \\
\hline
\end{tabular}

The results show that the vertical cart leads with a net benefit of 1.28. Due to the involvement in both horizontal and vertical motions, as well as the relatively high mass, this assembly has the highest lightweight potential. Generally speaking, the net benefit is causally connected to the potential for mass reduction. Based on these results, an initial lightweight concept is designed for the motion unit shown in Figure 4. 


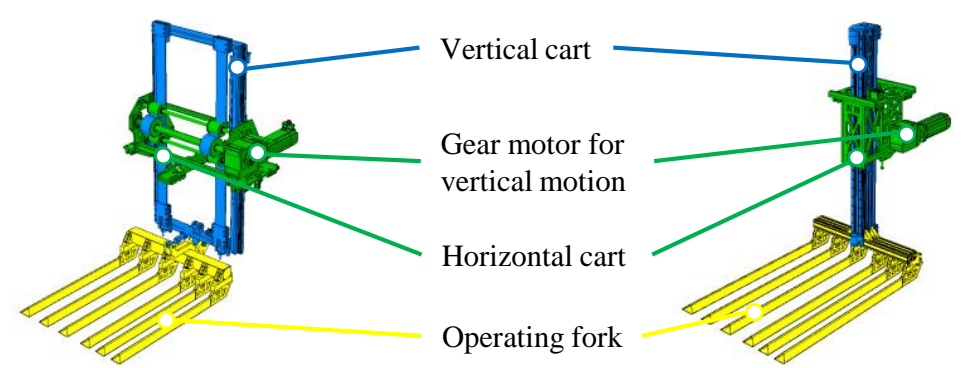

Figure 4. Old motion-unit concept (left) and new lightweight concept (right)

Due to the high lightweight potential of the vertical cart, this assembly was the first part to be tackled with regard to mass reduction. The new concept is the result of three iterative design steps and features a significantly narrower vertical cart. Therefore, the horizontal cart can also be made smaller, which also follows the lightweight-potential assessment (the vertical cart has the second-highest potential for mass reduction). For both carts, the material is changed from steel to (mainly) aluminum. In addition, the topology of the horizontal cart is optimized. On the operating fork, the number of parts used is reduced through functional integration. Altogether, the new concept reduces mass by $40 \%$, which is considerably over the initial target. Finally, this stage of the lightweight-design process enables costs for the new concept to be estimated, thereby deriving cost-benefit ratios for the assemblies to judge the lightweight solutions in more detail. The normalized costs (manufacturing and design with the horizontal cart as reference value) that were first related to the same amount of mass reduced (i.e., 30 $\%$ for every assembly) are shown in Table 5.

Table 5. Cost-benefit ratio for all assemblies

\begin{tabular}{|l|c|c|c|}
\hline & Horizontal cart & Vertical cart & Operating fork \\
\hline Net benefit $\left(\mathbf{B}_{\text {net }}\right)$ & 0.94 & 1.28 & 0.25 \\
\hline Normalized costs $(\mathbf{C})$ & 1 & 0.68 & 0.23 \\
\hline Cost-benefit ratio $\left(\mathbf{B}_{\text {net }} / \mathbf{C}\right)$ & $\mathbf{0 . 9 4}$ & $\mathbf{1 . 8 7}$ & $\mathbf{1 . 0 8}$ \\
\hline
\end{tabular}

The cost distribution shows a remarkable inversion between the horizontal cart and the operating fork compared to the net benefit (Table 4). While the net benefit of the operating fork is the lowest, the low cost of the lightweight solutions for the fork lift the cost-benefit ratio above the ratio of the horizontal cart. While the vertical cart demonstrates the highest cost-benefit ratio by far, the result suggests renewed investigation of the lightweight design for the horizontal cart. Due to overfulfilment of the project's mass reduction by $10 \%$ (40\% compared to the targeted $30 \%$ ), reversing some lightweight modifications to this cart might result in a more economical yet competitive and high-performance product.

\section{Critical discussion and outlook}

The implementation of the cost-benefit analysis for deriving lightweight potential seems an expedient approach for supporting designers in early development phases. The correlation of components (or assemblies) to benefit criteria in terms of mass enables a versatile set of lightweight motivations to be combined into a single statement with regard to lightweight potential. The application of a certain cost structure comprising different lightweight technologies to the investigated assemblies results in a more holistic economic view of lightweight projects. Valid information about the cost structures, however, is usually available at a later point during optimization projects. Nevertheless, the presented approach is able to support designers continuous over the course of the project when new data are fed into the analysis. The approach also proved flexible with regard to processing and implementing various kinds of criteria during the analysis. The question asked in the introduction of this paper (concerning where lightweight design should be applied) can thus be answered purposefully.

However, the evaluation example from Section 6 reveals several issues to be addressed in the ongoing lightweight project. While the approach proved useful in terms of effectiveness in deriving lightweight potential, a sensitivity analysis must be conducted to reveal the influence of some of the assumptions 
made. For instance, the quantification of the influence of the relocated mass on the oscillations of the entire machine must be examined in more detail. The assumption to validate this particular criterion can be supported by a simulation (e.g., finite element).

Finally, future research will apply the novel approach to different kinds of products to attempt to sharpen the methodological procedure in addition to testing the efficiency. To be entirely useful, the amount of time invested in the analysis of lightweight potential must match the quality of the outcome. In lightweight-design projects, this might be measurable in net profit because the approach supports the correct investment in the right amount of mass reduced.

\section{References}

Albers, A., Moeser, G. and Revfi, S. (2018), "Synergy effects by using sysml models for the lightweight design method extended target weighing approach", Procedia CIRP, Vol. 70, pp. 434-439.

Alonso, E. et al. (2012), "Evaluating the potential for secondary mass savings in vehicle lightweighting", Environmental science \& technology, Vol. 46 No. 5, pp. 2893-2901.

Blessing, L.T.M. and Chakrabarti, A. (2009), DRM, a Design Research Methodology, Springer, London. https://doi.org/10.1007/978-1-84882-587-1

Caldwell, B.W. et al. (2013), "Automotive lightweight engineering. A method for identifying lazy parts", International Journal of Vehicle Design, Vol. 63 No. 4, p. 364.

Cellini, S.R. and Kee, J.E. (2015), "Cost-effectiveness and cost-benefit analysis", In: Newcomer, K.E., Hatry, H.P. and Wholey J.S. (Eds.), Handbook of Practical Program Evaluation, 4th Ed, Jossey-Bass, San Francisco.

Cheah, L. and Heywood, J. (2011), "Meeting U.S. passenger vehicle fuel economy standards in 2016 and beyond", Energy Policy, Vol. 39 No. 1, pp. 454-466.

Farooq, A.A., Roth, R. and Kirchain, R (2018), "Lightweighting technologies: Analyzing strategic and economic implications of advanced manufacturing processes", International Journal of Production Economics, Vol. 206, pp. 268-279. https://doi.org/10.1016/j.ijpe.2018.10.003

Hao, H. et al. (2016), "The impact of stepped fuel economy targets on automaker's light-weighting strategy. The China case", Energy, Vol. 94, pp. 755-765.

Kim, H.-J. et al. (2008), "Model of cost and mass for compact sized lightweight automobiles using aluminum \& high strength steel", 2008 IEEE International Symposium on Electronics and the Environment, San Francisco, USA. https://doi.org/10.1109/SNPD.2007.507

Klein, B. (2013), Leichtbau-Konstruktion, Springer Vieweg Verlag, Wiesbaden. https://doi.org/10.1007/978-3658-02272-3

Kroll, L. et al. (2011), "Lightweight components for energy efficient machine tools", CIRP J. of Manufacturing Science and Technology, Vol. 4 No. 2, pp. 148-160.

Laufer, F., Roth, D. and Binz, H. (2018), "Supporting engineers in lightweight design: The Energy Distribution Analysis (EDA)", 15th International Design Conference, May, 21-24, 2018, Croatia, The Design Society, Glasgow, UK, pp. 829-840.

Laufer, F., Roth, D. and Binz, H. (2019), "Derivation of Criteria for Identifying Lightweight Potential - A Literature Review", Proceedings of the 22nd International Conference on Engineering Design (ICED19), Delft, The Netherlands, 5-8 August 2019. https://doi.org/10.1017/dsi.2019.274

Lewis, A.M., Kelly, J.C. and Keoleian, G.A. (2014), "Vehicle lightweighting vs. electrification. Life cycle energy and GHG emissions results for diverse powertrain vehicles", Applied Energy, Vol. 126, pp. 13-20.

Luedeke, T. and Vielhaber, M. (2014), "Holistic Approach for Secondary Weight Improvements", Procedia CIRP, Vol. 21, pp. 218-223.

Markel, T. and Simpson, A. (2007), "Cost-Benefit Analysis of Plug-In Hybrid Electric Vehicle Technology", The World Electric Vehicle Association Journal, Vol. 1, pp. 294-301.

Mishan, E.L. (1972), Cost-Benefit Analysis, George Allen Unwin LTD, London. ISBN 0-04-338043-3

O'Reilly, C.J. et al. (2016), "Life cycle energy optimisation. A proposed methodology for integrating environmental considerations early in the vehicle engineering design process", Journal of Cleaner Production, Vol. 135, pp. 750-759.

Posner, B., Binz, H. and Roth, D. (2014), "Supporting Lightweight Design Potential Assessment in the Conceptual Phase", Marjanović, D., Štorga, M., Pavković, N. and Bojčetić, N. (Eds.), In: Proceedings of the DESIGN 2014, 13th Internat. Design Conference. Zagreb, Croatia; The Design Society, Glasgow, UK, pp. 353-362.

Rinza, P. and Schmitz, H. (1992), Nutzwert-Kosten-Analyse, VDI Verl. GmbH, Düsseldorf. ISBN 3-18-400884-3 